\title{
REPERCUSSÃO DO SISTEMA NACIONAL DE SAÚDE NOS MODELOS ASSISTENCIAIS *
}

\author{
Taka Oguisso **
}

OGUISSO, T. Repercussão do Sistema Nacional de Saúde nos modelos assistenciais. Rev. Esc. Enf. USP, São Paulo, 14(2):147-164, 1980.

Estudo e análise do Sistema Nacional de Saúde, suas características e dimensões, modelos assistenciais vigentes no País, reflexões sobre as possibilidades de repercussão do primeiro sobre o segundo e, finalmente, o papel da enfermeira nesse contexto.

\section{INTRODUÇC̃O E HISTÓRICO}

0 assunto, apesar de já ter sido longa e amplamente discutido, pode ser considerado ainda, de grande atualidade, dadas as poucas modificações ocorridas no setor. Em que pese a enorme expansão econômica brasileira ocorrida na década de 1970 , é notória a precária condição de saúde em que vive grande parte da nossa população. Como disse o Prof. Roberto Santos, "não são poucos os brasileiros, em áreas rurais, cuja atual condição de saúde é a mesma de gerações passadas. Apesar de haver aumentado... a atenção atribuída à áera social, ainda é grande o seu atraso, para a população em geral, quando confrontada com a dinamização de várias atividades do setor econômico".

A existência de intima inter-dependência entre saúde e economia sugere uma análise histórica desse processo para melhor compreensão da situação atual, que nada mais é do que reflexo e conseqüência das opções passadas.

Essa análise, feita a seguir, foi baseada principalmente em obras de BRAGA e LUZ, que fizeram meticuloso trabalho de pesquisa sobre a matéria.

O desenvolvimento capitalista no Brasil teve início, neste século, com a exportação de café. A dinâmica dessa economia exportadora fez com que a saúde tivesse tratamento voltado para o combate a endemias e para o saneamento de portos e núcleos urbanos mais importantes, tais como Rio de Janeiro, São Paulo e Santos. Esses núcleos estavam ligados às atividades de comércio, financiamento, transportes e exportação cafeeira. Além disso, havia necessidade de se proporcionarem boas condiçōes sanitárias locais para as relações comerciais com o exterior e para atrair imigrantes, que constituiriam a mão de obra indispensável à formação do mercado de trabalho capitalista.

Por essa razão, Rodrigues Alves, ao assumir a presidência em 1902, deu início a obras de saneamento na Capital da República, visando o combate à febre amarela e malária. Em 1904, foi promulgada a lei de vacinação anti-variólica compulsória.

\footnotetext{
* Apresentado na I Jornada de Administração em Enfermagem da Bahia, 10 a 12 de dezembro de 1979.

* Docente Livre em Enfermagem, pela Escola de Enfermagem nAa Neri, da Universidade Federal do Rio de Janeiro; Professor Assistente da disciplina História e Legislação da Enfermagem e da Obstetricia da EEUSP.
} 
Essas medidas sanitárias foram tomadas para solução imediata de problemas agudos, porque poderiam comprometer o processo da economia cafeeira e ameaçar a população, dado o aspecto de calamidade e epidemia que poderiam assumir.

A acumulação capitalista cafeeira encontra grande prosperidade na década de 1920, quando também ocorre o surto de industrialização e urbanização, que passa a demandar melhores soluções para o problema da saúde e não apenas soluções limitadas ao atendimento do complexo de comércio exportador.

Carlos Chagas tem destacado papel nessa década, quando, ao criar o Departamento Nacional de Saúde Pública, estabeleceu, como atribuições federais: o saneamento rural e urbano; a propaganda sanitária; a higiene infantil, industrial e profissional; atividades de fiscalização; a saúde dos portos e o combate às endemias.

Anteriormente, como refere BRAGA, "as unidades de Saúde Pública existentes eram vinculadas aos governos estaduais e voltadas sobretudo para as capitais e principais cidades do interior".

Ainda foi na década de 20 que ocorreu a criação das Caixas de Aposentadoria e Pensões (CAPs), pela Lei n. 4 t682/23, mais conhecida como Lei Eloy Chaves, e que deu início ao seguro social no Brasil. Antes dela só existia a lei para indenização de acidentes do trabalho (1919) nas companhias de transporte e construção e nas fábricas.

Essas CAPs previam: assistência médica curativa e fornecimento de medicamentos; aposentadoria por tempo de serviço, velhice e invalidez; pensões para dependentes; auxílio pecuniário para funeral. Eram organizadas por empresas e do seu financiamento participavam a União, os empregadores e os empregados. Os ferroviários, ligados ao sistema de transportes, e os estivadores e marítimos, ambos estreitamente vinculados ao complexo exportador, foram os primeiros a serem beneficiados pelo seguro social, aqueles em 1923 e estes em 1926. Os demais trabalhadores só foram incluídos depois de 1930, quando a indústria passou a dominar o processo capitalista.

Na década de 30 instala-se no País o período de getulismo, com elevado grau de autonomia. Coincide, pois, com a fase de acelerado processo de industrialização e urbanização, o que agrava as condições de vida e saúde da população.

É criado o Ministério da Educação e Saúde, em 1930, com dois Departamentos Nacionais, o de Educação e o de Saúde.

Entretanto, é no aspecto social do trabalho que se concentram as maiores atividades do governo, na década, com a regulamentação de diversos aspectos trabalhistas, sindicalismo atrelado ao governo, criação de institutos de aposentadoria e pensões para outras categorias de trabalhadores, etc. Nessa ocasião, a questão social, em geral, e a da saúde, em particular, começam a fazer parte da problemática do poder, porque a classe trabalhadora crescente, vivendo em precárias condições de saúde, higiene, habitação, etc., passa a exigir efetivação e ampliação das políticas sociais. 
Assim, a partir de 1930 surge a estrutura do setor saúde que é dividida em dois sub-setores: o de saúde pública e o de medicina previdenciária. 0 primeiro predomina até meados de 1960 ; o segundo começa a se ampliar a partir da década de 1950 e passa a predominar, em termos de política estatal, a partir de 1966.

Essa alteração no panorama do setor saúde ocorre apesar dos graves problemas de saúde pública existentes na época, o que deixou, até hoje, uma herança de endemias ainda não solucionadas, apesar da política de ação campanhista do Ministério da Saúde.

Durante o periodo de predominância do sub-setor saúde pública ocorreram alguns fatos importantes tais como: a fundação, em 1942, do Serviço Especial de Saúde Pública (SESP), a elaboração, em 1948, de diversos planos de saúde a partir do Plano Salte e a separação do antigo Ministério da Educação e Saúde em dois Ministérios distintos. Essa separação, ocorrida em 1953, acarretou, no dizer de M. LUZ, um "esvaziamento institucional do setor saúde, enquanto setor estatal, em proveito da Educação". Essa situação parece perdurar até hoje, pois, em recente declaração publicada na imprensa em São Paulo, o atual Ministro da Educação e Cultura, Eduardo Portela, diz que somente a Secretaria de Ensino de $10^{\circ}$ e 2..$^{\circ}$ graus, subordinada ao seu Ministério, é maior que todo o Ministério da Saúde.

O SESP, criado em convênio com o governo americano, durante a Segunda Guerra Mundial, teve grande atuação na prestação de assistência médico-sanitária no País, dando cobertura em áreas econômica e militarmente estratégicas, como a da produção de borracha, na Amazônia.

Naquela ocasião, o Brasil necessitava intensificar a exploração de matérias primas indispensáveis ao esforço ide guerra das Nações Unidas, o que justificava plenamente a organização de um Serviço Especial de Saúde Pública para a Amazônia, de onde se extraía a borracha. De acordo com o convênio, ao SESP foram atribuídas, além das atividades de saneamento, profilaxia da malária e assistência médico-sanitária às populações da Amazônia, também o preparo de profissionais para o trabalho de saúde pública, não só o aperfeiçoamento de médicos e engenheiros sanitaristas, mas ainda, a formação de enfermeiras de saúde pública e o treinamento de outras categorias técnicas.

Posteriormente houve ampliação do convênio e o SESP passou a operar no Vale do Rio Doce, dando assistência aos trabalhadores na reconstrução da Estrada de Ferro Vitória-Minas, objetivando acelerar a exportação de minérios. Também o Estado de Goiás foi beneficiado pelo SESP que passou a assistir aos trabalhadores que atuavam na extração de mica e cristal de rocha.

O Plano Salte (saúde, alimentação, transporte e energia) pretendia redistribuir médicos pelo território nacional, pois existia na época, como ainda hoje existe, desigualdade na distribuição geográfica desses profissionais. Essa desigualdade seria corrigida, de acordo com os autores do Plano Salte, mediante uma política intervencionista do Estado no campo da assistência médico-social e a introdução de modificações na formação profissional, isto é, incentivar a prática de clínica geral e desencorajar a opção por especialidade. 
Outros Planos se sucederam ao Plano Salte, nesse período e mesmo após 1965, também com malogro, total ou parcial, devido a desconsideração das variáveis sócio-econômicas. Assim foram: o Plano de Saúde da Comissão do Vale do São Francisco, de 1948, que construiu 43 hospitais; o Plano de Assistência Médica aos Municípios, de 1956, que pretendia levar "assistência médica, de forma simples e realista, sem entraves burocráticos, a todos os municípios brasileiros"; o Plano de Expansão Demográfica dos Médicos, de 1965, elaborado pela Associação Médica Brasileira, que era uma réplica do Plano do Ministério da Saúde, de 1956; o Plano de Saúde do Estado do Amazonas, e 1968, que importou 56 unidades médico-assistenciais pré-fabricadas, totalmente equipadas; o Plano Naciol nal de Saúde de Leonel Miranda, (1968), que favorecia a atenção médica do setor privado, buscando universalizar a medicina assistencial em detrimento dos serviços de saúde pública.

Um acontecimento mais importante do que todos esses planos de saúde foi provavelmente a convocação da III Conferência Nacional de Saúde, em 1963, por esta ter definido como deveriam ser os planos de saúde, isto é, "mostrando as íntimas relaçōes entre saúde e economia; definindo as necessidades da existência de uma estrutura permanente de saúde", de nível de responsabilidade municipal, assistido tecnicamente pelos níveis estadual e federal, sem superdimensionamentos. Recomendava ampla utilização de pessoal de nível auxiliar e definia as funções das unidades locais de saúde, que poderiam ser desempenhadas sem a presença do médico.

Em 1960, quando a Previdência Social era composta por seis institutos, foi promulgada a Lei Orgânica da Previdência Social (LOPS). Nessa ocasião, todos os institutos foram pressionados no sentido de elevarem os gastos em assistência médica. A fixação do percetnual desse gasto no total das despesas dependia da situação econômico-financeira do instituto e da força da pressão sindical. Assim, houve expansão crescente da assistência médica, a partir de 1960, que levou alguns institutos a ultrapassarem os limites atuariais previstos. Em conseqüência, começa a se esboçar uma séria crise financeira devido ao efeito cumulativo dos benefícios de aposentadoria e pensões e a desigualdade no crescimento entre a massa de contribuintes ativos e a de trabalhadores inativos. Ante a inexistência ou insuficiência de rendas do patrimônio e capital, houve necessidade Ide sucessivas elevações nas taxas de contribuição, que passaram de $3 \%$ para $5 \%$, depois $6 \%, 7 \%$ e finalmente $8 \%$. A solução adotada foi a fusão dos institutos e a criação do Instituto Nacional de Previdência Social.

Antes de 1964, não havendo planejamento ordenado, os fatos se sucediam ao sabor das pressões e reivindicações dos usuários, segurados e trabalhadores em geral.

Com o estabelecimento, em 1964, de novo sistema de governo, com grande autonomia, foi implantada a política de reformulação que se fazia necessária, dada a conturbação geral da sociedade. No setor saúde, ocorreram diversos eventos muito importantes a partir dessa data, tais como: a unificação dos institutos de aposentadoria e pensões e a criação do Instiuto Nacional de Previdência Social (INPS), em 1966; a Reforma Administrativa (Decreto-lei 200/67) que atribuiu ao Ministério da Saúde, entre outras, as funções de formulação e coordenação da política nacional de saúde; a promulgação de nova Constituição em 1967, emendada em 1969, que estatuiu como competência da União o estabelecimento e a 
execução de planos nacionais de saúde, além de legislação sobre normas gerais de defesa e proteção da saúde.

Nessa época houve grande expansão das instituições médicas, com proliferação de escolas médicas, crescimento da demanda estudantil por vagas e por verbas para a prática hospitalar, expansão da rede hospitalar privada conveniada ou contratada com a Previdência Social e consequente redução da prática liberal a medicina nos grandes centros urbanos.

Como conseqüência, o início da década de 70 , é marcado por uma crise dos sistemas de saúde, que se vai agravando na proporção das necessidades não satisfeitas pelos modelos assistenciais existentes.

Somente a partir de 1974 , em face da necessidade de reciclagem do modelo ou "milagre" econômico, consubstanciada no II Plano Nacional de Desenvolvimento (1975-79), é que o Governo Federal passa a se preocupar efetivamente com o problema dos sistemas de saúde, reconhecendo a urgência de adequá-lo à responsabilidade de cumprir novos papéis e racionalizar as práticas existentes.

Concomitantemente, houve ainda a criação do Conselho de Desenvolvimento Social (CDS), pela Lei n. $6.118 / 74$, com competência para apreciar a Política Nacional de Saúde formulada pelo Ministério da Saúde, bem como os planos setoriais dos Ministérios da Previdência e Assistência Social e de Educação e Cultura, referentes à assistência médica, formação profissional médica e paramédica e fixação das diretrizes para sua execução.

Nesse clima surge, finalmente, a Lei n. ${ }^{\circ} 6.229$, de 17 de julho de 1975, dispondo sobre a organização do Sistema Nacional de Saúde. Para coroar a promulgação dessa Lei é também convocada a V Conferência Nacional de Saúde, em agosto de 1975, cujo relatório final recomenda a regionalização dos serviços e a hierarquização em níveis de complexidade crescente, como processo eficaz para descentralizar a prestação de serviços básicos de saúde e racionalizar o uso da capacidade instalada e os recursos humanos.

Em suma, a solução para a crise do sistema de saúde seria a extensão à população da assistência primária.

\section{O SISTEMA NACIONAL DE SAÚDE}

As práticas de saúde na sociedade são realizadas através de um sistema formal e de outro informal. O primeiro seria aquele desenvolvido, segundo Seixas, "graças a ações empírico-místicas, sem respaldo institucional-legal, como por exemplo, a medicina de folk, o curandeirismo, etc."; o segundo seria desenvolvido por meio de "ações empírico-científicas e com respaldo institucional-legal".

Cada um desses sistemas corresponde, na realidade, a um conglomerado de outros sub-sistemas. Além do curandeirismo, há outras técnicas curativas trazidas de países de culturas milenares, tais como acupuntura, ioga e outras consideradas pré-científicas, como as dietas naturais, macrobióticas, balneoterapia, etc. A utilização desses recursos não deve ser considerada, como refere Campos, apenas "como mecanismo compensatório da inacessibilidade dos serviços da medicina cien- 
tífica, pois elas vicejam em países onde esse problema não existe e entre nós persistem nas áreas urbanas".

O sistema empírico-científico também pode ser decomposto em vários subsistemas, que classicamente se apresentam como setores público e privado. Entre a instituições públicas oficiais é da maior importância o Ministério da Previdência e Assistência Social, pela magnitude de seus gastos com serviços de saúde, seja mediante prestação direta, seja através da compra, desses serviços, de terceiros (setor privado, entidades filantrópicas, etc.). Esse Ministério, de tão grande comprador, tornou-se comprador único (monopsônico), configurando um tipo de monopólio inverso.

Portanto, havia e há, no Brasil, um sistema de saúde, que não deve ser confundido com o "Sistema Nacional de Saúde", institucionalizado por força da Lei n. ${ }^{\circ} 6.229 / 75$, com a intenção de provocar mudanças no sistema de saúde existente.

Considerando que sistema é o conjunto de partes mutuamente relacionadas por meio de comunicações e bloqueios para a realização de objetivos comuns, a sua aplicação no setor saúde, como em qualquer outro, implica na existência de autoridade, poder de decisão e legitimidade do poder, o que é conferido através do respectivo embasamento legal.

Em resumo, apenas para fixar a construção teórica de sistemas, pode-se dizer que todo sistema tem uma finalidade e é constituído basicamente por in put, processo e out put. Este comunica-se com a entrada, in put, por uma alça cibernética para retroalimentação do sistema, que assim reinicia o processo.

O sistema de saúde, como qualquer outro, está inserido em sistemas maiores, dos quais ele é sub-sistema. Podem ser identificados pelo menos dois sistemas maiores, o meta-sistema, ou seja, a organização social, e o eco-sistema, ou o ambiente físico. 0 sistema de saúde funciona, em relação a tais sistemas, em estado de equilíbrio dinâmico, ajustando e reajustando seu desempenho de acordo com o fluxo de informações e com os ditames do sistema maior e, concomitantemente, influindo no seu comportamento.

A visão sistêmica da realidade permite observar os seus componentes e seus pontos de influência como um todo, possibilitando atuação em um ponto qualquer para corrigir, à distância, outros pontos que não sofreram interferência direta.

Essa interferência, via de regra, vinha sendo feita ao nivel de processo, isto é, sobre o órgão produtor dos serviços de saúde. Ao sair do processo, a população remanescente constitui-se em alça cibernética, de controle, sobre o sistema. A interferência pode ser feita também ao nível de insumos da entrada, ou seja, sobre os setores: formador de recursos humanos para a saúde, produtor e distribuidor de medicamentos, alimentos e equipamentos; ou sobre o setor financeiro.

Transformadas as aspirações populares em fluxo de informações desse sistema cibernético, as fontes retroalimentadoras deverão ser decodificadas pelos centros decisórios. Estes podem interferir a esse nível por meio da formulação de uma política de saúde, que reajuste o processo ou oriente a tomada de decisões quanto a áreas de mudança a fazer e quanto à destinação de recursos para as mesmas. 
A política de saúde deve, pois, servir de base para a implantação de qualquer sistema de saúde racional, ainda mais, em caso como o do Brasil, onde esse sistema é pluri-institucional e os recursos encontram-se pulverizados.

0 fluxo de recursos financeiros constitui decisão do meta-sistema e depende, não apenas do produto total do trabalho no país, mas sobretudo da valorização social da saúde, em cuja função são estabelecidos os limites de gastos dos serviços na área da saúde.

A ideologia de racionalização e modernização adminitrativa que vem marcando o setor saúde, na década atual, constitui suporte para as transformações então operadas.

Assim, as instituições de saúde transformam-se, ao longo do tempo, adaptando-se às alterações do ambiente em que estão inseridas. A adoção do aborto em certos países constitui exemplo desses ajustes do sistema de saúde.

Quando coexistem uma multiplicidade de instituições de saúde, a tendência é que uma ou algumas delas tornem-se hegemônicas e passem a impor seu modelo às demais. É o caso do Brasil onde, por direito, o Ministério da Saúde tem a hegemonia legal e a responsabilidade de formular a política nacional de saúde. Em contrapartida, existe a hegemonia de fato do Ministério da Previdência e Assistência Social, cuja dotação orçamentária global é várias vezes superior à destinada ao Ministério da Saúde (foi de dezesseis vezes, em 1975).

$\mathrm{Na}$ discussão da proposta sistêmica para reorganização sanitária do país, é necessário ter como ponto de partida as finalidades dos serviços de saúde. Hoje é pacificamente aceito que os determinantes básicos do nível de saúde de uma população estão situados fora do âmbito de ação dos serviços de saúde, o que é facilmente comprovável, no dizer de Campos, pela "estagnação no estado geral tde saúde da população brasileira, apesar de vultosos gastos em saúde". Outro exemplo é o aumento da mortalidade infantil ocorrido na segunda metade da década de 60, o que está claramente relacionado com a diminuição do salário real, conforme pesquisas realizadas.

Illich, em seu livro "Expropriação da Saúde", situa a ação médica como a terceira causa determinante do estado global, sendo antecedido apenas pelo meio ou modo de vida e pelas atividades de saneamento.

É dentro desse panorama que deveria ser implantado o Sistema Nacional de Saúde.

A Lei $n .^{\circ} 6.229 / 75$, logo em seu art. $1 .^{\circ}$, define e delimita os campos de ação de seus componentes, que além dos cinco Ministérios (Saúde, Previdência e Assistência Social, Educação e Cultura, Interior e Trabalho) inclui os Estados, Distrito Federal, Territórios e Municípios.

Reiterando o que já foi dito e escrito por muitos estudiosos deste assunto, essa Lei, ainda não regulamentada entre nós, teve seu texto prejudicado por imprecisões e ambiguidades terminológicas, pelo uso excessivo de advérbios que não indicam com precisão o volume ou os limites das competências. 
A regulamentação da Iei $n .^{\circ} 6.229 / 75$, deverá buscar uma solução para a crise dos sistemas de saúde nesta década e, ao mesmo tempo, traçar uma política setorial de saúde mais consentânea com a realidade.

Essa política será provavelmente baseada de acordo com a IV Reunião Especial de Ministros da Saúde das Américas, de setembro de 1977, na extensão de cobertura de serviços de saúde com as estratégias de assistência primária e participação da comunidade.

Desde essa ocasião, a tônica da assistência primária vem permeando todos os discursos institucionais de organizações internacionais dedicadas à saúde, como a Organização Mundial de Saúde (OMS), inclusive a Organização Panamericana de Saúde (OPS) e também o Fundo das Nações Unidas para a Infância (UNICEF). Em setembro de 1978 foi convocada a Conferência Internacional sobre Assistência Primária de Saúde, em Alma Ata, URSS, cujo relatório publica a Declaração de Alma Ata, exortando à urgente e eficaz ação nacional e internacional a fim de estimular e por em prática a assistência primária de saúde no mundo inteiro, e particularmente nos países em desenvolvimento.

Recentemente, quando da comemoração do $900^{\circ}$ aniversário da Proclamação da República no Brasil, o novo Ministro da Saúde, Waldyr Arcoverde, em seu segundo pronunciamento oficial declarou: "Caminhamos para o estabelecimento de uma integração de atividades com a criação de uma rede básica de saúde, na qual se apoiará o Sistema Nacional de Saúde, estrutura que nos permitirá a democratização do atendimento e a elevação dos níveis de saúde em todo o território nacional".

Comentam os jornais desse dia, que parece ter sido dado o primeiro passo para a efetivação do Sistema Nacional de Saúde, com a aprovação, pelo Conselho de Desenvolvimento Social, da expansão por todo o território do Programa de Interiorização das Ações de Saúde e Saneamento (PIASS); esta expansão é considerada como meta prioritária do atual Governo, embora já tenha sido esboçada em alguns Estados do Norte e Nordeste desde a administração passada.

Realmente, ver a Política Nacional de Saúde ser aprovada pelo Conselho de Desenvolvimento Social e ver o seu sistema ser regulamentado era e ainda é um sonho acalentado nos últimos doze anos pelos seis Ministros que administraram a saúde do País, a partir de fevereiro de 1967, quando o Ministério da Saúde assumiu legalmente a competência de formulação e coordenação de uma política para o setor, de acordo com o Decreto-lei 200/67, da Reforma Administrativa.

Outro passo dado anteriormente foi a Portaria Interministerial $n .^{0}, 001 / 78$, de 26 de julho de 1978, quando os Ministros da Saúde e o da Previdência e Assistência Social, tendo em vista promover a implantação do Sistema Nacional de Saúde, estabeleceram diretrizes para a execução dos Serviços Básicos de Saúde.

Nesse documento explicitam que a "execução da Lei $n .^{\circ} 6.229 / 75$ não resultará da expedição de apenas um documento de caráter regulamentar; textos sucessivos darão apoio à progressiva consolidação dos atos necessários à consecução dos objetivos do Sistema Nacional de Saúde"; mas, já estabelecem que a supervisão dos planos e programas será realizada pelos dois Ministérios, que a instalação de Serviços Básicos terá precedência sobre quaisquer outros de maior 
complexidade; que a tecnologia a ser utilizada será a mais simplificada possível. De acordo ainda com essa Portaria, os Serviços Básicos seriam constituídos pelos níveis elementar e primário, sendo o primeiro atendido "por pessoal auxiliar de enfermagem, em tempo integral, com formação mínima de três meses e sob supervisão da Unidade de Saúde Pública de nível primário".

$O$ nível primário poderia ser com ou sem internação. $O$ atendimento previsto seria nas quatro especialidades básicas: médica, cirúrgica e materno-infantil.

Esse documento, entretanto ,assinado em final de mandato dos dois ministros, não teve suficiente divulgação e nem estudos para sua operacionalização. Observa-se na área da enfermagem uma impropriedade, quando menciona "pessoal auxiliar de enfermagem com formação minima de três meses". Ou se trata da categoria "Auxiliar de Enfermagem", cuja formação está regulamentada, por via supletiva ou regular ,mas não em três meses; ou se trata de pessoal atendente que, no INAMPS, constitui a categoria "auxiliar operacional de serviços diversos".

Documento semelhante foi assinado no dia 11/9/79 conjuntamente pelos Ministros da Saúde (Dr. Mario Augusto de Castro Lima) e da Previdência e Assistência Social (Dr. Jair de Oliveira Soares), consubstanciado no Aviso-Circular n. ${ }^{\circ}$ 493/GM-Bsb, enviado a todos os Governadores de Estado e Territórios. Por esse documento, os Ministros solicitam a cada Govrenador a constituição de grupo de trabalho para elaboração do Plano Integrado de Saúde do Estado, com a particpação de representantes locais dos dois Ministérios, Delegado Federal de Saúde e Superintendente do INAMPS, sob a coordenação da Secretaria Estadual de Saúde. Enfatizam o binômio Saúde/Previdência Social, já dentro das diretrizes do III Plano Nacional de Desenvolvimento, especialmente no que se refere à "regionalização de saúde, que deverá sofrer necessário processo de compatibilização, no sentido de unificar os órgãos executivos locais dos Ministérios da Saúde e da Previdência e Assistência Social e da Secretaria Estadual de Saúde".

Talvez, agora, com a posse no Ministério da Saúde de um ex-presidente do INPS, aquela Portaria e esse Aviso-Circular venha a encontrar possibilidades de concretização. De qualquer forma, observa-se tendência histórica na fusão entre INAMPS e Ministério da Saúde, tendo essa hipótese sido até admitida, conforme noticiário da imprensa.

Já anteriormente havia uma multiplicidade de órgãos, dentro do próprio Ministério da Previdência e Assistência Social, para cuidar da assistência médica - INPS, IPASE, FUNRURAL, etc. Após a criação do SINPAS há apenas um órgão - o INAMPS - para realizar esse trabalho. Embora o INAMPS tenha um orçamento várias vezes superior ao do Ministério da Saúde, é este que tem acesso direto ao Presidente da República, que tem a competência de formular e coordenar a política de saúde no país, enfim, tem "status" de Ministério. A saúde é um assunto importante demais para não ficar situado no primeiro escalão do governo, pois mesmo assim, durante tantos anos, ela não recebeu a atenção de que necessitava. Agora que a comunidade também está começando a se mobilizar, especialmente nessas experiências municipais tais como Campinas, Londrina, Niterói, etc., é importante que o maior mandatário do País continue informado e assessorado por um de seus Ministros e não por vias indiretas de uma autarquia, fundação ou outra qualquer. Ainda que constituam experiências à margem do Sistema Nacional de Saúde representam tentativas válidas para 
extensão de cobertura, regionalização e hierarquização dos níveis de assistência à saúde.

\section{OS MODELOS ASSISTENCIAIS}

A pluri-institucionalização, que caracteriza a assistência à saúde no Brasil, configura uma situação em que, segundo os Anais da VI Conferência Nacional de Saúde, de 1977, descreve que "chegaram a se enumerar, apenas no âmbito federal, 71 entidades realizando atividades de saúde ou correlatas".

Partindo da clássica divisão do sistema formal de saúde em setores público e privado, são encontradas em cada um deles as mais diversas modalidades.

No setor público existem as de nível federal, estadual e municipal e as de administração indireta, como as autarquias subordinadas a cada um dos níveis citados.

Ao nivel federal estão os dois Ministérios o da Saúde e o da Previdência Social; neste último destaca-se a autarquia vinculada, denominada Instituto Nacional de Assistência Médica da Previdência Social. No Ministério da Saúde merece menção especial a Fundação Serviço Especial de Saúde Pública, que embora vinculada a esse Ministério, sempre foi dotado de grande flexibilidade técnica e administrativa e apresentava características especiais que a diferenciava de outros serviços de saúde.

Ao nivel estadual são encontradas basicamente as Secretarias Estaduais de Saúde, com seus Centros de Saúde e Hospitais.

Ao nivel municipal existe correspondência dessas atividades com denominações diversas: Secretaria da Higiene, da Saúde Municipal, da Promoção Social e Saúde, etc.

Além dessas, ainda existem os serviços de saúde das corporações militares, que também têm seus correpondentes aos níveis federal e estadual.

No setor privado, também complexo, podem ser encontradas entidades de fins sociais e filantrópicos, assim denominadas as que foram declaradas de utilidade pública, por decretos governamentais dos três níveis ou de um deles; as cooperativas de prestação de serviços, as empresas de medicina de grupo e, finalmente, os consultórios particulares onde médicos, dentistas e outros profissionais exercem a clínica nos moldes tradicionais, isto é, mediante pagamento direto ou indireto pela clientela.

Entretanto, mesmo as entidades filantrópicas do tipo das Santas Casas e Hospitais de Beneficência, passaram a receber, também, uma clientela paga, predominantemente previdenciária, embora continuassem usufruindo dos benefícios da "utilidade pública".

Esse é o complexo heterogêneo do sistema produtor de serviços de saúde no Brasil. A entrada de novos produtores no mercado é, segundo Fuchs, citado por Araújo, restrita nesse sistema, dadas as dificuldades de formação do profissional de saúde, especialmente do médico, cujo currículo escolar é longo e de custo elevado (em termos de gastos efetivos e em termos de custo de oportunidade). Sobre este assunto, a Congregação da Faculdade de Medicina da Universidade de São Paulo, em manifesto público, denunciou que o "poder público estava 
interessado em baratear o custo da assistência médica através do aumento numérico de médicos, sem qualquer preocupação com a qualidade. A conseqüência lógica foi o nivelamento por baixo, a comercialização da medicina assistencial através de empresas lucrativas e a diminuição proporcional do rendimento dos médicos ... o País passou a formar médicos em número muito superior às suas necessidades, pretendendo dar assistência médica gratuita em padrỗes muito superiores às suas possibilidades econômicas. Como resultado lógico, tem hoje o Brasil grande número de médicos de baixa qualificação e grande número de pacientes mal assistidos".

Outra característica do sistema produtor de serviços de saúde é a ausência de certos mecanismos normais no mercado de bens e serviços ,tais como a propaganda e a concorrência de preços; no caso da saúde são mal vistos e, mesmo, expressamente condenados pelo Código de Ética. Entretanto, nos Estados Unidos, já houve recente permissão para que os médicos norte-americanos recoressem "à publicidade, caso pretendam aplicar sua clientela".

Ainda segundo Fuchs, essas práticas restritivas dificultam uma avaliação econômica do out put e do desempenho do sistema produtor. Além disso, a prática da prestação de alguns serviços a indigentes constituiria uma demanda sem suporte financeiro. Mas, como todo serviço tem um custo, alguém estará pagando. Hoje, o serviço público avocou a si o pagamento de serviços prestados a essa parcela da população, denominada "carente" ou quarto extrato social, coberta atualmente pelo próprio INAMPS, que incorporou os serviços médicos da Legião Brasileira de Assistência (LBA). É o processo da universalização da Previdência Social que, tendo estendido sua cobertura aos trabalhadores rurais, a partir da implantação do Sistema Nacional de Previdência e Assistência Social (SINPAS), aoclheu também a população carente.

É interessante observar a evolução dos serviços de saúde nos Estados Unidos, país de economia capitalista dos mais ortodoxos. Em 1964, foi aprovado o $\mathrm{Me}$ dicare, um programa estatal que assegura serviços de saúde gratuitos aos maiores de 65 anos de idade (13\% da população); em seguida, 1971, foi aprovado outro programa, o "Medicaid" (Medicalli Indigent) em que o governo federal e estados custeiam os serviços de saúde prestados a indivíduos com renda familiar abaixo de US $\$ 3000$ anuais: finalmente, está criando um seguro estatal por empresas particulares. Como se vê, mesmo num país de alto nível de desenvolvimento, há tendência em insereir os serviços de saúde no universo dos serviços de interesse público.

No Brasil, também já houve situação semelhante, no caso do acidente do trabalho, quando em 1967 o INPS assumiu toda a cobertura do seguro, que era privado.

De acordo com dados oficiais, em 1976, antes da criação do SINPAS, apenas $7,4 \%$ (7.667.000) dos habitantes no território nacional estavam desamparados, fora dos sistemas sociais de proteção à saúde.

A Previdência Social desenvolve a prestação de serviços de saúde basicamente dentro de três linhas: serviços próprios, contratados e em convênio. 
Os serviços próprios são realizados por meio de 540 Postos de Assistência Médica e 39 hospitais.

Os Postos de Assistência Médica, em muitos casos funcionam apenas como repassadores ou, segundo Mello, "como instrumento de encaminhamento quase sistemático de pacientes para internação nas casas de saúde da rede contratada. É que inexiste impedimento legal do exercício do cargo de médico do quadro do INPS (atual INAMPS) simultaneamente com a situação de médico credenciado do mesmo INPS (atual INAMPS)".

Os hospitais próprios, de modo geral, são especializados, bem equipados e voltados para o ensino e a pcsquisa, daí o seu custo operacional relativamente elevado.

Os serviços contratados, segundo dados de 1976, citados por Mello, contavain com 15.261 médicos credenciados para atendimento ambulatorial e 165.977 leitos funcionando em 2.808 hospitais entre os privados, filantrópicos e de ensino. Esse tipo de serviço é pago mediante apresentação de fatura individual por paciente (conta nosocomial) com discriminação da natureza das despesas efetuadas, desde serviços profissionais e diárias até medicamentos e material de curativos e exames complementares de diagnóstico e tratamento.

Os serviços em convênio compreendem diversas modalidades de relacionamento e remuneração, das quais se destacam as abaixo enumeradas.

a) Convênios com empresas, firmados com cerca de 4.000 empresas empregadoras, geralmente de grande porte. Desse total, mais de $70 \%$ estão localizadas no Estado de São Paulo, dos quais $80 \%$ na Grande São Paulo. Em razão desses convênios, é transferido do INAMPS o encargo de toda a assistência médico-hospitalar para os serviços das empresas empregadoras ou por elas contratadas. Entretanto, permanecem no INAMPS a responsabilidade dos casos nas especialidades de tisiologia, psiquiatria, cirurgia cardíaca, alguns tipos de neurocirurgia, transplantes, implantes e outros riscos que, pelo valor do tratamento, são classificados como catastróficos. O INAMPS reserva a si o direito de fiscalizar os padrões de atendimento e participa de seu custeio através da restituição, à empresa empregadora, de um valor fixo, mensal, por empregado, correspondente a $5 \%$ do maior salário mínimo vigente no País. Essas entidades médicas privadas, contratadas pelas empresas empregadoras para prestação de assistência médica mediante recursos rstituidos pela Previdência Social, constituem em geral os grupos médicos ou medicina de grupo, que estão organizadas dentro da lógica empresarial de finalidade lucrativa. Esta finalidade marca a tendência para redução de despesas e pode, muitas vezes, comprometer o tipo ou a qualidade da assistência médica prestada.

Além da medicina de grupo que se relaciona com a Previdência Social de forma indireta, existem ainda as cooperativas médicas. Estas constituem, também, uma entidade privada de prestação de serviços de assistência médica que funciona com recursos obtidos junto à Previdência Social, através de pagamento por unidades de serviço.

Tal modalidade também deixa a cargo dos serviços próprios do INAMPS as prestações médico-hospitalares de custo mais elevado e os grupos de segurados mais suscetíveis ao risco de adoecer. 
As cooperativas médicas funcionam tentando conciliar objetivos contraditórios: de um lado buscam reduzir as despesas como a medicina de grupo; e de outro, cada cooperado pretende produzir cada vez mais unidades de serviço, que é afinal a sua remuneração.

b) Convênio com Sindicatos; são restritos ao atendimeto ambulatorial, com pagamento de um subsídio fixo mensal.

c) Convênio com Universidades; instituídos em outubro de 1974. Há contribuição mensal variável em função do número de altas hospitalares, cujo valor é atribuído de acordo com o tipo dessa alta; clínica, cirúrgica (discriminadas as intervenções em grande, médio e de pequeno porte), obstétrica (parto normal ou cirúrgico); a esse subsídio é acrescentada uma parcela especifica para atendimento ambulatorial. A respeito desse tipo de Convênio-padrão, a Comissão de Ensino Médico manifestou-se dizendo que "os hospitais de ensino passaram a vivenciar de modo mais efetivo os problemas de necessidade de atenção médica da comunidade e, em adição, passaram a perceber remuneração pela assistência prestada aos pacientes previdenciários... e que pode a Previdência Social ter a oportunidade de aplicar fórmulas mais adequadas de remuneração de serviços médicos, um vez que esses convênios eliminam o método de pagamento por unidades de serviço, capaz de gerar distorções na intensidade de aplicação de medidas de diagnóstico e de tratamento".

d) Convênio com serviços oficiais, limitados ao atendimento em ambulatório e aos casos de urgência, mediante pagamento de subsidio fixo mensal. Foi celebrado com governos estaduais e municipais. No caso de necessidade de hospitalização, o paciente é encaminhado para internação em uma casa de saúde da rede contratada.

e) Acidentados do trabalho. Essa clientela foi pouco valorizada na legislação do SINPAS. Ela está sujeita a uma legislação própria especifica que lhe confere direito à percepção de benefícios e assistência médica de carácter acidentário. A grande diferença entre um cliente acidentado e um previdenciário consiste principalmente em que o primeiro é sempre um segurado, isto é, trabalhador ativo que contribui para a Previdência Social. $O$ segundo pode ser um segurado ou seu dependente. Essa clientela é atendida quase em sua totalidade pela rede contratada.

f) Assistência Patronal. É aquela prestada aos funcionários da Previdência Social através de hospitais contratados, médicos e outros profissionais credenciados, com pagamentos por atos médicos e cirúrgicos, onde o servidor participa com uma parcela.

Em São Paulo existe ainda a modalidade CIAM (Centro de Integração de Assistência Médica), que tem personalidade jurídica, cuja direção é composta paritariamente por representantes da Secretaria de Saúde e do INAMPS. Âlém de poder contratar pessoal, especialmente de nível médio, pode permitir consultas médicas nos Centros de Saúde, da Secretaria de Saúde, recebendo o médico, através do CIAM, o pagamento por ato médico.

A assistência médica na Previdência Social vem sendo orientada no sentido da privatização, especialmente no campo hospitalar, o que é demonstrada pelos 
gastos efetuados; $90 \%$ em assistência médica do ex-INPS destinaram-se à compra de serviços da rede privada e $80 \%$ deste montante em internações hospitalares. Em 1978, segundo a publicação "INAMPS em dados", houve 7.781.188 internaçöes hospitalares, no Brasil, dos quais 89,8 nos contratados, $6,9 \%$ nos convênios e apenas $3,3 \%$ nos serviços próprios. Esses dados referem-se apenas à clientela urbana, pois houve 1.876 .867 internações da clientela rural, atendidos através de serviços em convênio (Quadro I).

\section{QUADRO I}

INAMPS - BRASIL - Total de internaçð̃es, 1978

\begin{tabular}{lll} 
CLIENTELA URBANA & -7.781 .188 \\
CLIENTELA RURAL & -1.876 .867 \\
\hline & 9.658 .055
\end{tabular}

CLIENTELA URBANA - Internaçōes segundo tipo de serviço e porcentagem, 1978.

\begin{tabular}{lrr}
\hline Serviços & Internações & $\%$ \\
\hline Próprios & 253.362 & 3,3 \\
Contratados & 6.986 .084 & 89,8 \\
Convênios & 541.742 & 6,9 \\
\hline Total & 7.781 .188 & 100,0 \\
\hline
\end{tabular}

Fonte: INAMPS EM DADOS - 1978

$\mathrm{Na}$ parte da assistência ambulatorial o quadro modifica-se um pouco, pois, do total de 150.644.375 atendimentos da clientela urbana, 38,3\% foram realizados em serviços próprios, $32,6 \%$ em contratados e $29,1 \%$ sob convênio.

QUADRO II

Movimento ambulatorial de consultas - Brasil - 1978 - INAMPS

Clientela urbana - total de consultas médico-odontológicas, segundo tipos de serviços, 1978

\begin{tabular}{|c|c|c|c|c|c|c|}
\hline Serviços & $\begin{array}{l}\text { Cons. } \\
\text { médica }\end{array}$ & $\%$ & $\begin{array}{l}\text { Consulta } \\
\text { odontológ. }\end{array}$ & $\%$ & Total & $\%$ \\
\hline $\begin{array}{l}\text { Proprios } \\
\text { Contrat. } \\
\text { Conven. }\end{array}$ & $\begin{array}{l}53.720 .018 \\
41.487 .008 \\
34.805 .525\end{array}$ & $\begin{array}{l}41,3 \\
31,9 \\
26,8\end{array}$ & $\begin{array}{l}3.965 .089 \\
7.685 .178 \\
8.981 .557\end{array}$ & $\begin{array}{l}19,2 \\
37,3 \\
43,5\end{array}$ & $\begin{array}{l}57.685 .107 \\
49.487 .008 \\
43.787 .082\end{array}$ & $\begin{array}{l}38,3 \\
32,6 \\
29,1\end{array}$ \\
\hline Total & 130.012 .551 & 100,0 & 20.631 .824 & 100,0 & 150.644 .375 & 100,0 \\
\hline
\end{tabular}

Fonte: INAMPS EM DADOS - 1978

CLIENTELA RURAL - Total de consultas médico-odontológicas atendidas nos convênios, 1978 , Brasil.

$$
\begin{aligned}
& \text { Consultas médicas } \quad-15.399 .061 \\
& \text { Consultas odontologicas - 8.378.281 } \\
& \text { Total }-23.777 .342
\end{aligned}
$$

A expansão verificada nos serviços curativos e seu carácter privatizante, embora, tenha um aspecto negativo, pois a demanda é originada por condições deficientes de vida que afetam a maioria da população pobre, desde a subnutrição até ambientes patogênicos de moradia e trabalho, tem também um aspecto positivo, o de ter proporcionado maior acessibilidade (mesmo que precariamente) à medicina e odontologia científicas. 


\section{POSSIBILIDADES DE REPERCUSSĀO}

Na verdade, até hoje, pode-se dizer que ambos, isto é, o Sistema Nacional de Saúde e os modelos assistenciais vigentes coexistem pacificamente, sem interferências significativas.

Todavia, existem muitas possibilidades de repercussão, o que será possível através da implantação de uma política de saúde que leve em consideração a realidade brasileira como um todo. Deve caracterizar-se por uma política de mudança: mudança da situação de saúde; mudança que promova entrosamento institucional e que elimine o desperdício de recursos, etc. Mas, não significa que o sistema político seja mudado ou deva ser mudado.

A política de saúde deve abranger os problemas prioritários do país e os recursos, assim entendidos os recursos físicos (equipamentos, insumo, estabelecimentos de saúde); os humanos (que profissionais ou ocupacionais formar, como formar e como utilizar); os conhecimentos científicos e tecnológicos e os financeiros.

De acordo com a estrutura nosológica, observa-se que $90 \%$ dos problemas de saúde dependem de soluções simples. Sobre estes deveriam ser concentrados os esforços assistenciais. Mas, a realidade é que $92 \%$ dos esforços são aplicados sobre $10 \%$ de problemas sofisticados (diálises, cirurgias cardiacas, transplantes, implantes, etc.).

No Brasil, os sistemas formador e utilizador de recursos humanos ainda não estão bem entrosados. Continua a haver formação de técnicos da área da saúde com ênfase no aspecto eminentemente curativo, embora já se devesse saber que, curando o doente, não se está eliminando a doença. Por outro lado, a estrutura do sistema vigente de assistência médica previdenciária exerce grande papel nesse processo de formação, pois privilegia as especializações e os especialistas em detrimento do trabalho do generalista.

A respeito desse problema, um passo foi dado recentemente pela Previdência Social, ao regulamentar o Parecer MEC $n .^{\circ} 5.241$, de $10^{\circ}$ de setembro de 1978, da Comissão Nacional de Residência Médica. Nos termos desse Parecer, os programas de Residência Médica deverão ser oferecidos em instituições de saúde com adoção da "residência por área, modalidade preferencial, com prioriade para a Clínica Médica, Cirurgia Geral, Pediatria, Obstetrícia, Ginecologia e Medicina Preventiva ou Social".

Para 1980, o INAMPS, em São Paulo, oferece residência médica apenas para essa área preferencial.

De qualquer forma, tanto na área médica, como na enfermagem e outras profissões ou ocupações da saúde, deve-se ainda levar em conta a integração docente-assistencial. A prática de campo é condição para formação dos recursos humanos necessários ao sistema utilizador, uma vez que é através dessa prática que se proporcionará a criação de reais oportunidades para o aprendizado. Assim, mesmo o sistema formal deveria privilegiar o ensino fora dos muros da escola, onde a aprendizagem tende a se realizar de forma passiva e em ambiente artificial. Enfatizar a formação em serviço pode favorecer a unificação de funções 
ainda estanques, tais como a docência, supervisão e prestação de serviços nos seus diversos niveis, e com isso forjar novos perfis profissionais necessários par a prática.

O desenvolvimento dos conhecimentos científicos e tecnológicos adequados constitui problema prioritário, pois dele depende a criação ou a implantação de novos modelos assistenciais. Daí a importância da construção de uma tecnologia setorial apropriada à realidade brasileira. Entende-se por tecnologia apropriada aquela explicitada, segundo Vieira, "em termos dos conhecimentos científicos que as embasam; da simplicidade e do baixo custo de sua utilização e manutenção; do consumo de formas de energias alternativas e viáveis em pequenas unidades rurais; da sua polivalência; da possibilidade de sua administração por pessoal auxiliar, etc. Trata-se de fazer ao inverso o caminho que foi percorrido desde o século passado, que concentrou nos hospitais, de modo absoluto, a tecnologia da saúde. Naquela época ,o problema tratava de se concentrar ao máximo para aplicar em escala industrial; agora, pelo contrário, tem-se que desconcentrar ao máximo para aplicação em pequena escala".

O projeto do III Plano Nacional de Desenvolvimento, 1980-1985, no tocante às políticas setoriais, não prevê articulação entre Educação e Saúde. Neste último setor, estabelece as linhsa de atuação para o quinqüênio, enfatizando o combate às endemias, o fortalecimento de atividades relacionadas com a medicina preventiva, a descentralização das atividades para os níveis estaduais e municipais, na medida das possibilidades, em busca da universalização da proteção social.

Enfim, a regulamentação da Lei n..$^{\dagger a}$ 6.229/75, do Sistema Nacional de Saúde, cujas bases políticas foram delineadas na VI Conferência Nacional de Saúde, em 1977, pressupõe uma implementação através da regionalização e hierarquização das ações de saúde. Também a VII Conferência Nacional de Saúde, a se realizar em Brasília, de 24 a 28 de março de 1980, terá por finalidade reunir profissionais e autoridades para o estudo e debate de temas relacionados com os principais objetivos do Governo Federal no Setor Saúde, visando o aperfeiçoamento dos programas nacionais e a integração dos órgãos participantes do Sistema Nacional de Saúde. Terá como temário específico a expansão das ações de saúde, mediante serviços básicos, e a estrutura fundamental do Sistema Nacional de Saúde, com a finalidade de elevar, social e economicamente, os níveis de vida da população do país. Em resumo, a última Conferência Nacional teve, assim como a próxima terá, como denominador comum a busca de uma fórmula de implementação da extensão de cobertura por meio de um sistema de articulação intersetorial, não só entre as instituições formadora e utilizadora, mas também entre os Ministérios da Saúde e da Previdência Social, e ainda entre os níveis estadual e municipal, na zona urbana e rural.

Sem essa integração, dificilmente será possivel alcançar a meta para o ano 2.000, proposta pela Organização Mundial de Saúde, como um desafio para todas as nações, que é "Saúde para todos".

\section{CONSIDERAÇÕES FINAIS}

Cabe também às enfermeiras responder ao desafio proposto pela Organização Mundial de Saúde, dispondo-se a assumir sua parcela de responsabilidade 
na execução dos cuidados primários de saúde, caminho viável para se chegar a um nível aceitável de saúde geral em futuro previsível.

A revitalização do Programa de Interiorização das Ações de Saúde e Saneamento (PIASS), considerado como meta prioritária do atual Governo, constitui uma das alternativas para efetivar a regionalização e hierarquização das ações de saude, a partir de uma rede de pequenas unidades periféricas para execução das ações básicas de saúde, preventivas e curativas.

0 custo crescente da assistência à saúde, como fenômeno universal, e a experiência já realizada em outros países em desenvolvimento com a implantação 'de um sistema de assistência primária para diminuição de custos e extensão de cobertura populacional, assim como a Declaração de Alma-Ata, de setembro de 1978, comprovam que a prestação desse tipo de assistência constitui um dos recursos para consecução de um nivel de saúde aceitável para todos. Para isso, esse sistema deve funcionar como porta de entrada, com livre trânsito da cilentela, que deve ser referida e contra-referida para todos os níveis de assistência, de acordo com critérios previamente estabelecidos, para não cair num sistema de saúde com duas faces: uma para ricos e outra para pobres.

Essa estratégia da regionalização e hierarquização implica necessariamente na utilização de recursos humanos disponíveis de acordo com o nível de complexidade das ações. Será preciso formar equipes multiprofissionais para supervisão, treinamento, educação continuada e sobretudo para preparo de pessoal auxiliar de nivel médio e elementar para execução dos cuidados primários.

Nessa equipe multiprofissional, o papel da enfermeira será fundamental, considerando que a maioria do pessoal auxiliar é representada pela área da enfermagem. Caberá à enfermeira, pois, preparar esses auxiliares, em larga escala, para que eles possam disseminar os conhecimentos e ao mesmo tempo ser capazes de respeitar, valorizar e incorporar conceitos e práticas populares nas ações de proteção e recuperação de saúde. Surgiu, inclusive num dos relatórios dos grupos de trabalho do I Simpósio Nacional sobre Política de Saúde, realizado em Brasília, 1979, a recomendação que se possibilitasse o uso da flora e da homeopatia, hoje uma especialidade médica reconhecida, na assistência médica.

Evidentemente, a operacionalização de uma reforma setorial de tal monta não será fácil, nem poderá se efetivar a curto prazo, não só devido à própria situação conjuntural, política e sanitária, à multiplicidade de instituições de saúde, mas, principalmente, porque os profissionais da saúde, não só médicos, mas também as enfermeiras, não estão preparados para essa forma de prestação de assistência. Todos somos produtos de um tipo de formação que sempre esteve eminentemente voltado para a prática assistencial curativa, com base em especialidade. Poucos conseguiram libertar-se desta forma monopolizadora e isolacionista do conhecimento.

Contudo, para que ocorra a ocupação do espaço social, político e econômico que está se abrindo ao setor saúde, é necessário envidar todos os esforços para adequar as práticas ao modelo assistencial da extensão de cobertura.

Este é o desafio proposto às enfermeiras. Há que se assumir, como classe e como profissionais da saúde, a responsabilidade de desempenhar o papel que 
corresponde a cada um no seu respectivo campo de trabalho, seja este de assistência, de ensino ou de administração. Em cada um desses campos há algo a fazer em termos de assistência primária. Atualizar-se sobre o assunto é obrigação urgente e inadiável para todas as enfermeiras, para depois realizar pessoalmente atividades de supervisão, treinamento, orientação de pessoal nas unidades de saúde, ambulatórios ou mesmo em hospitais; ou ainda, adaptar currículos e progra. mas de ensino dos cursos de graduação, de técnico e de auxiliar de enfermagem; ou simplesmente criar condições, facilitar o desempenho dessas atividades, valorizar ou incentivar a execução das ações de assistência primária.

É dessa forma que deveria ser respondido o grande desafio feito pelo Diretor Geral da Organização Mundial de Saúde, à pergunta "o mundo precisa de enfermeiras?"

Sim, o mundo precisa de enfermeiras, porque estamos dispostas a prestar assistência primária de saúde a pessoas, sejam sadias ou doentes; porque pretendemos assumir o papel que nos cabe de contribuir efetivamente para que a meta de "Saúde para todos" no ano 2.000 seja realmente alcançado.

OGUISSO, T. Effects of the National System of Health on the health services offered to the people. Rev. Esc. Enf. USP, São Paulo, 14(2):147-164, 1980.

Analysis of the National System of Health in Brazil and of the health services offered to the people; of the possible effects of the former over the latter; and of the role of the nurse in this context.

\section{BIBLIOGRAFIA}

ARAUJO, J. D. As peculiaridades do mercado de serviços de saúde. Revista de Administração Pública, Rio de Janeiro, 11(3): 97.109, jul./set. 1977.

BRAGA, J. C. S. A questão da saúde no Brasil: um estudo das políticas sociais em saúde pública e medicina previdenciária no desenvolvimento capitalista. Campinas, 1978. (monografia de mestrado Depto. de Economia, UNICAMP).

BRASIL. Leis, decretos, etc. Portaria Interministerial n. $001 / 78$ de 26 de julho de 1978 . Diário oficial, Brasilia, 31 jul. 1978, p. 11.922 - 11.924. Estabelece diretrizes para execução dos serviços básicos de saúde.

CAMPOS, O. Contribuição do estudo dos sistemas de saúde. In: ENCONTRO DE ESTUDOS POPULACIONAIS, 1.॰, Campos de Jordão, 1978. Anais. s.l.p/ ABEP s.d/ p. 265-279.

CORDEIRO, H. 'Sistema de saúde: o estado e a democratização da saúde. In: ENCONTRO DE ESTUDOS POPULACIONAIS, $1 .{ }^{\circ}$, Campos de Jordão, 1978. Anais... /s.1.p./ABEP/s.d./.

EDUCAÇAO. O Ministro desabafa e fala sobre o ensino, sobre a censura... Jornal da Tarde, São Paulo, 6 nov. 1979 , p. 2.

ENSINO médico em crise: manifesto da Faculdade de Medicina da USP. Clência e Cultura, São Paulo, 30(12): 1473-75, dez. 1978.

ILLICH, I. A expropriação da saúde. 3. ed. Rio de Janeiro, Nova Fronteira, 1977.

LUZ, M. T. As instituições médicas no Brasil: instituição e estratégia de hegemonia. Rio de Janeiro, Graal, 1979.

MATOS. A. D. Organização do Serviço Especial de Saúde Pública. Rev. Serv. Saúde publ., Rio de Janeiro, 15(1): 116-129, 1970 .

MATTOS, A. V. A enfermagem e o Sistema Nacional de Saúde. In: CONGRESSO BRASILEIRO DE ENFERMAGEM, 30., Belém, 1978. Anais... Brasília, ABEN, 1978.

MÉDICOS dos EUA podem usar a publicidade. Folha da Tarde, São Paulo, 26 out. 1979. p. 13.

MELlO, C. G. Planejamento de saúde e desenvolvimento econômico. Revista de Administração Pública, Rio de Janeiro, 11(3): 81-96, jul./set. 1977.

- A formação do médico generalista e a medicina previdenciária. Campinas, Associação Brasileira de Educaçāo Médica, 1978 (mimeografado).

ORGANIZACION PANAMERICANA DE LA SALUD. IV reunion especial de ministros de salud de las Americas informe final. Washington, 1978. (Documento oficial, 155).

PROGRAMA de interiorização vai cobrír o país. O Estado de São Paulo, São Paulo, 15 out. 1979. p. 58.

PROPOSIÇOES alternativas para o atendimento das necessidades. básicas de saúde nos países em desenvolvimento. /s.1.p./ Fundo das Nações Unidas para a Infância, 1979. (Doc. E/ICEF/L. 1322).

SANTOS, R. A saúde no contexto do desenvolvimento social e económico. In: SIMPOSIO SOBRE POLITICA NACIONAL DE SAUDE, 1.०, Brasilia, 1979. (mimeografado).

SEIXAS, J. C. Sistema nacional de saúde. In: Conferência Nacional de Saúde, 5a., Brasilia, 5.8 agosto, 1975. 